\title{
DISCUSSION OF THE RESOLUTIONS ON FINANCES
}

$\Lambda$ T THE Annual Meeting of the Society held in Ottawa in January last, three of the Resolutions submitted for consideration (Nos. 2, 3, and 4) dealt with financial changes in our organization of considerable magnitude and importance. These three resolutions were referred to a Committee headed by Mr. P. McEwen for consideration and report, with the understanding that eventually the recommendations of the Committee would be submitted to the membership-at-large in the form of a letter ballot.

Mr. McEwen's committee has not yet completed its work, but it has been suggested to the writer that, in anticipation of the referendum which is to be submitted, a statement of some of the phases of the problems under survey should be presented to the members in this issue of the Chronicle so that each voter may have a fairly complete picture of the situation, to the end that his vote, when cast, shall be as informed as possible and that he will be prepared to support his vote with the actions his views imply.

Following are four statements; three presented by members of the Northern Ontario and Victoria Sections (which sponsored one or other of the Resolutions in question) and one by myself containing some of the comments. I have submitted to Mr. McEwen's committee.

Eric Druce

\section{Proportional Representation at Annual Meetings}

The illusion of isolation, created by living on an island, which is further heightened by mountain barriers which physically separate most of British Columbia from the other eight provinces of Canada, has perhaps been partly responsible for the Victoria Section's sponsorship at two successive Annual Meetings of the Society of resolutions dealing with the question of securing adequate and proportional representation. This perseverence might also be partly promoted by feelings akin to those which are frequently expressed in the political sphere, namely that British Columbia, and the Maritimes too, though members in the Canadian Confederation have been placed in a disadvantageous economic position, especially in relation to the central (eastern) provinces. Whether this is or is not true, it is most probable that the proposal was principally due to the difficulty of securing any, let alone adequate, representation, because of the heavy travelling expenses incurred in attending meetings, which have usually been approximately twenty-eight hundred miles distant.

The resolution respecting proportional representation, as submitted to the Meeting in Ottawa, January 23, 1940, read as follows:

"Whereas the opinions of members living in outlying parts of the Dominion are unlikely to carry adequate weight owing to the paucity of representation, and

Whereas the Victoria Section believes that some solution can be found;

Be it Resolved that the General Executive Committee discover and recommend some method of proportional representation at Annual Meetings, to be voted upon by letter ballot in time for use at the next Annual Meeting." (Resolution No. 9). 
The resolution was defeated by the Meeting, although in 1939 the same resolution (in essentials) was adopted. As Article VIII of the Constitution provides that five or more members may initiate a letter ballot involving an amendment, it would seem that this resolution should have only been introduced to the Meeting for the purpose of securing an expression of opinion.

The Victoria Section could rightfully petition for a letter ballot, but this has been found unnecessary since provision for voting by proxy at general meetings was made in the Letters Patent, which were granted on the ninth of September, 1915, under the Ontario Companies Act, creating and constituting the Canadian Society of Forest Engineers. This section is worded thus:

"(17) Votes may be given either personally or by proxy, and the instrument appointing a proxy shall be in writing under the hand of the appointer, or if such appointer is a Corporation, under its common seal, and shall be attested by at least one witness, and no person shall be appointed a proxy who is not a member of the Corporation;"

Representation at Annual Meetings in Relation to SECTIONAL MEMBERSHIP

CANADIAN SOCIETY OF FOREST ENGINEERS

Attendance at Annual Meetings

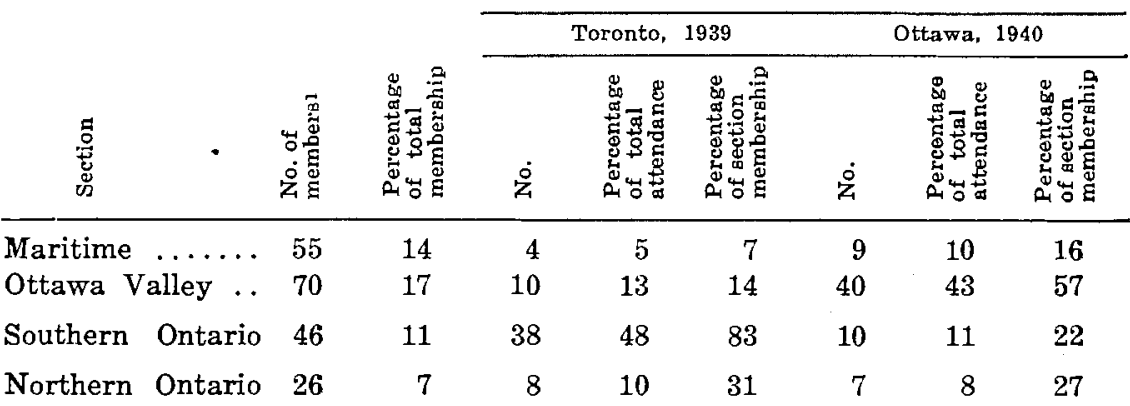

Northwestern

$\begin{array}{llllllllll}\text { Ontario } & \ldots & 21 & 5 & 5 & 6 & 24 & 3 & 3 & 14\end{array}$

$\begin{array}{lllllllll}\text { Vancouver } \ldots \ldots & 28 & 7 & 0 & 0 & 0 & 3 & 3 & 11\end{array}$

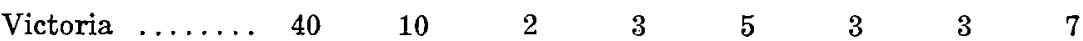

Percentage of total member-

ship $\ldots . . .$.

${ }^{1}$ Members in good standing January 15, 1940.

2Includes recently formed Prairie Provinces Section.

Includes approximately 65 members resident in Quebec.

${ }^{*}$ Quebec 8, Ontario 1, Prairie Provinces 5, U.S.A. 3. 
Although the last two Annual Meetings have been remarkably well attended by 20 to 23 per cent. of all the members, the non-representative character of the meeting is borne out in the preceding table which has been prepared from statistics supplied by the Secretary-Treasurer. Over 40 per cent. of the attendance has originated from the nearest Section, as would be normally expected, but this is a much higher proportion than the number of members in that Section bears to the whole membership of the Society. Sections at intermediate distances were approximately represented by the proper proportion, but those Sections farthest from the Meeting were insufficiently represented.

Unless a system of proportional voting is used, it would seem to be a most undemocratic procedure for the Annual Meeting to decide the fate of resolutions, whether pertaining to constitutional changes or not, which have been sponsored by a Section or Sections. Let us briefly consider a case. A resolution to be presented at an Annual Meeting may be passed by a large majority or even unanimously at a Section meeting which may easily be attended by at least 75 per cent. of the members registered in this particular Section. It is not unlikely that a whole evening may have been fully devoted to the discussion of half a dozen or even fewer resolutions. At the Annual Meeting a much greater number of resolutions must be dealt with in quite possibly less time and, moreover, at the end of two busy days by not more than $20^{1}$ per cent. of the Society's members. Of this number, almost half represent only one of the eight organized Sections.

While the conduct of the Society may not have suffered in the past through lack of attention to this question, it would nevertheless seem to be a fitting time for this Society to maintain those democratic principles for which the country is engaging in war.

\section{A. P. MacBean,}

Chairman, Victoria Section Committee. (Committee also includes E. H. Garman

\section{A Discussion of Resolutions 3 AND 4} and J. Benton.)

Although the aims of these resolutions seemed clear to the Victoria Section when they were submitted, other resolutions to the Annual Meeting proposing a change in membership fees have clouded the issue. I am therefore glad to accede to a request for an elaboration of the intent of the Victoria Section in forwarding these resolutions. Though not discussed by the Section, I hope these notes will interpret the reasons that led to the proposals sponsored by them.

When Resolution No. 3 was considered by the Victoria Section it had no relation to any other resolutions regarding fees which were subsequently presented to the Annual Meeting. The proposal for a graduated scale of membership fees was aimed to provide a larger revenue to meet the growing needs of the Society. We felt that the Excutive Committee should be in a stronger financial position, with respect to administration of the Society's business, and particularly to allow larger scope for the development in format and content of the Chronicle.

\footnotetext{
${ }^{1}$ All the members registered at the Meeting do not attend every session.
} 
While believing that a flate rate is the simplest method of collecting membership fees, we think that any increase in the present flat rate would work a hardship on the members in the lower wage groups. We feel that a graduated scale is the best method of increasing fees without a large loss in membership, and is in keeping with the democratic nature of our organization, but realize that in some cases it will be necessary for the individual member to assess his dues; however, this would be a matter purely between the individual and the treasurer, and readily adjusted. The income groups defined in the resolution are purely arbitrary and based on our experience in Victoria. It may be necessary to adjust them to the findings of the Craig Salary Committee for all Canada in order to produce a reasonably larger revenue than the present rate of five dollars per member. On the best available estimate from Mr. R. D. Craig's figures for salary rates the classification proposed would increase the annual revenues about $\$ 1.90$ per member. This amount would provide four extra issues of the present Forestry Chronicle if the money were used for this purpose alone. The scale of fees was worked out for the Victoria Section of 37 members; on this basis the proposed scale would produce $\$ 281.00$, an amount 50 per cent. greater than the total of the present fees to the Society from the same group of members. It has been suggested that the scale of dues is not consistent with the salary groups, but it was graded in this way to keep down the proposed fees of the lowest class and keep the highest membership fee within reasonable bounds for the member who is willing to support the Society. We cannot direct the work of the Executive, but we can try to get a bigger and better Chronicle, and we can only attain increased efficiency in both respects by strengthening the sinews of the Society.

The point of emphasis in Resolution No. 4 of the Annual Meeting is that Sections remote from the place of Annual Meeting find that the cost of sending even one member to the meeting is too great for them to finance. The resulting disproportionate attendance at these meetings is not in the best interests of the Society as a whole. This point is illustrated in the article by Mr. MacBean in this number of the Chronicle which shows that a large proportion of members present at Annual Meetings is drawn from the locality of the meeting place. To somewhat counteract this trend the resolution was drawn with the intent to give all Sections a better chance of being represented.

The scheme as we visualize it is not to endeavour to pay the entire expenses of any delegate, but to create a fund, the whole of which will be disbursed annually in proportion to the distance the respective Sections are separated from the place of the Annual Meeting, to an accredited representative from each Section of the Society. It would not be disbursed on the basis of the number of Sections or delegates, but on a mileage basis in amounts proportionate to the ratios of the distance of the respective Sections from the meeting place to the sum of the distance of all Sections from the meeting place. Each Section represented at the Annual Meeting will pay the registration fee of one accredited representative, and thereby becomes qualified to participate in the fund. The fund so disbursed shall be the sum earmarked by the Executive for the purpose, amounting to one dollar per active member of the Society, and the amount raised by payment of a registration fee of $\$ 10.00$ by the representative of each Section. The registration fee is not an imperative part of the resolution but it is considered to be necessary to make 
the fund large enough to be effective and also place part of the cost directly with the Sections.

Two years ago the Victoria Section raised its own dues from $\$ 1.00$ to $\$ 2.00$ and set aside onerthird of the total dues to help finance representation at Annual Meetings.

\section{Ed. Note-}

\section{E. H. Garman.}

The following table shows the aggregate, one-way, mileages travelled by a single representative from each of the seven outlying sections to meetings at the various section centres, (Regina is the assumed centre for the Prairie's Section) and the aggregate round-trip fares incurred by them. This statement does not include meals, berths, hotel, or any other expenses than railway fares based on standard rates.

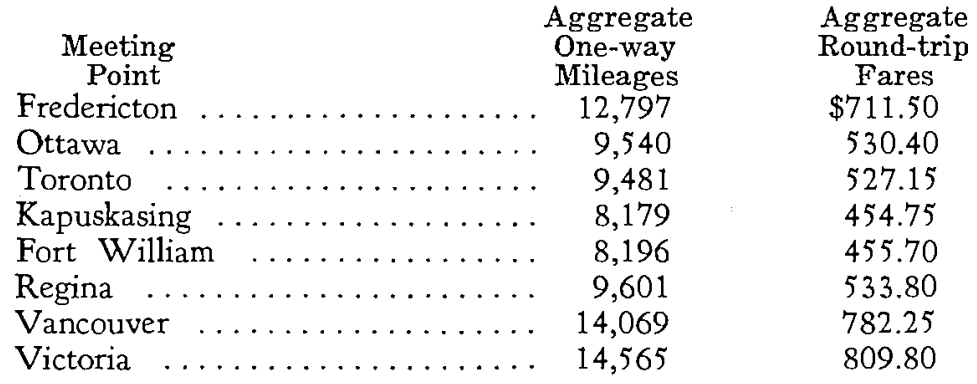

\section{This Question of Annual Fees}

At the last annual meeting of the Society, in January, several resolutions, dealing with increase in dues, were presented to the assembled members for their consideration. The proposal sponsored by the Northern Ontario Section requested the membership to give careful consideration to the question of the employment of a full-time, paid executive and the consequent increase in dues to fifteen dollars per year with a view to putting the scheme into operation in 1941. The following is an attempt to justify our opinion that this radical change is essential if we wish the Society to become a strong organization and to take its deserved place in the national life of this Dominion.

If we, as a Society, ever expect to influence the electorate or the governments, in the moulding of Dominion or Provincial forest policies, we must first attain some unanimity of thought and purpose among ourselves. We are a group, the sum total of whose technical training, experience and ability could, if the proper steps were taken to consolidate our talents and publicize our views, do much more in shaping the thoughts and opinions of Canadians on forestry matters than we are doing at present.

We are working along these lines now but the time, energy and thought that our appointed secretary and editor can apply to the affairs of the Society is obviously limited. They owe much to their employees and can give only a portion of their spare time to the direction of the Society. We are in the fortunate position of having appointed offcers who are applying far more effort to their jobs than they are adequately compensated for by their honoraria. They are now spending practically all their spare time in the interests 
of the Society to the detriment of their social and family life. We cannot count on being able to carry on thus indefinitely, being opportunists to the extent of availing ourselves, as a Society, to such more or less gratuitously rendered services. Furthermore, with all due respect to their efforts, they cannot be as effective as a competent full-time executive would be, in ensuring the Society's taking its rightful place in the life of the nation. In short, our secretary and editor are carrying too heavy a burden now, yet we all feel that more and faster progress should be made. Therefore, would not a fulltime paid executive be the best solution?

The Northern Ontario Section believes that under the present set-up we, as members of the Canadian Society of Forest Engineers, can expect very little more in the way of benefits, services or advantages than we are receiving now. If the Society had a full-time secretary manager we feel that we are justified in eventually expecting the following returns:

1. An improvement and increase in our own capacities to carry on Forestry work. This would be brought about by a more constant exchange of problems and opinions with a consequent broadening of the individual's perspective.

2. The Society to be in a position to intelligently advise either government or industry on any question dealing with forestry matters. This should include the backing or criticizing of any forestry plans or projects that the governments may put forward from time to time. The Society should also be able to endorse or refute articles on forestry subjects appearing in news. papers or magazines. When our Society can do this, recognition as the authority on forestry matters in Canada is bound to come, and our Society will become as well known and as respected as other generally recognized professional organizations.

3. As a direct result of the above, an improvement in our own status as individuals with respect to our jobs, whether in governmental or private employ.

4. The Society to set up an "Employment Service" to assist member foresters, temporarily unemployed, in their search for work. It should be aware of vacancies and pass this information on to members through our publications. Through a better knowledge of the requirements of industry and governmental agencies this may lead to the creation of new jobs to the benefit of all concerned.

An officer with an agreeable but forceful personality should be able to do a great deal to unify the various sections of the Society and to interpret the problems and views of one section to the members of other sections. This of course, will entail a certain amount of travelling, and if possible, the secretary manager should visit each section at least once a year. Therefore, the Society must be prepared to provide funds for this purpose, if it is to get optimum results from the employment of such a man.

Many members maintain that, with a paid officer, individual interest and effort on the part of the membership would wane. This, of course, would depend upon the person selected, but, if the right man were appointed, the reverse should be the case. A good full-time executive should get more cooperation from the members and the Society should make better progress towards its aims and ideals. 
The problem of picking the right man for the position is of paramount importance. We would require someone of experience following graduation from a forestry school. He must have a knowledge of forestry both theoretical and practical, a certain amount of experience in office organization, a good command of the English language and some knowledge of routine publishing and editing methods. It would also be advantageous if he could both speak and write French. He would need to be somewhat of an idealist and above all would have to have the interests of the Canadian Society of Forest Engineers at heart. A minimum salary for an officer filling these qualifications should not be less than $\$ 2,500$ per annum.

With a full-time executive and sufficient funds to permit it, there should be more issues of the Chronicle per year and a wider circulation. This should make it a valuable advertising medium to many companies which are not availing themselves of its use at present. A permanent officer should, during his travels, be able to make contacts that would result in increased advertising and do much towards making the Chronicle pay its own way

From a review of the early struggles of similar organizations, notably the Quebec Society of Forest Engineers, and the American Society of Foresters, it appears that they did not make much progress until they employed a fulltime executive officer and secured a certain amount of governmental recognition. We often complain of this lack of recognition. How can we expect the Canadian Society of Forest Engineers to obtain acknowledgment as the authority on forestry matters in Canada, until we are in a position to advise governments or industry on questions where they obviously need advice? We are making headway in this direction now and the preliminary steps have been taken, but much remains to be done. Are we not expecting the well-nigh impossible of our executive to handle a job of this magnitude in their spare time? Would not a full-time officer be an immense aid to them, and hence to the society in its work? We believe he would be.

The following is a tentative budget drawn up by Mr. Eric Druce, which is considered adequate by the Northern Ontario Section.

Estimated Expenditures:

Salaries:

Secretary-Manager (annual) $\ldots \ldots \ldots \ldots \ldots \ldots, 2,500.00$

Clerical (12 mos. @ 80.00) ................ 960.00

Auditing ............................ 40.00

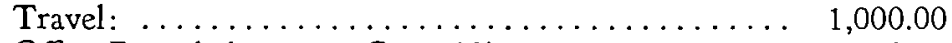

Office Rental (12 mos. @ 15.00) ................ 180.00

Publications:

6 Chronicles@250.00.................... 1,500.00

6 Bulletins@75.00 ........................ 450.00

Office Equipment, Supplies \& Expense . . . . . . . . 300.00

Miscellaneous ....................... $\quad 70.00$

$7,000.00$

Estimated Revenue:

Advertising in Chronicle: 10 pages @ 75.00....... $\quad 750.00$

Subscriptions (100@3.00) ................. 300.00

To be derived from membership fees: ......... 
Some of the above items necessitate an explanation not recorded in the previous pages. The $\$ 80.00$ per month allowance for clerical assistance is a minimum. As the secretary manager would be away visiting the various sections part of his time, this would require someone with a certain amount of initiative and ability to maintain the office work during his absence. The position would also require an ability to take shorthand dictation, competence with a typewriter, a fair command of the English language and some know. ledge of editing and proof reading.

Regarding publications, it has been suggested that a Chronicle should be issued monthly. The proposal of six Chronicles per year constitutes an interim step and would enable the executive to see if sufficient material would be available to fill the twelve issues suggested. Last year Chronicles cost on the average $\$ 205.00$ per issue, Bulletins $\$ 60.00$. Mr. Druce has increased these average amounts to permit larger issues of both publications and, in the case of the Chronicle, more profuse illustrations.

Under the heading of revenue, Mr. Druce increased the price per page for advertising and the price of subscriptions fifty percent. This increase is justified on the basis of six numbers being issued in place of the four published at present. He also has made some allowances for increased advertising and circulation which he believes would result from the employment of a full-time officer.

According to the above budget $\$ 5,950.00$ must be raised annually from the membership fees. The Northern Ontario Section believes that this can only be done by a direct levy of $\$ 15.00$ per member per year. We also contend that provision should be made to carry for two years members who, due to unemployment, are unable to pay their dues. This is a feature of most professional organizations.

It has been suggested that a sliding scale of dues be levied based on salary received. While we agree with this in principle, there are several factors which would make it extremely difficult of operation. These are as follows:-

1. Salary alone is not a true indication of ability to pay. That is, a single man with no dependents and a salary of $\$ 1,200$ per year should be in a position to pay higher dues than a married man with a salary of $\$ 2,000$ per year and with a family of three or four.

2. The first essential in working out such a scheme is a knowledge of the salary of each member. In the past this has been impossible to ascertain and we see no reason why it should be feasible now. Most members in private employ and certainly all private industry would object to any attempt made to secure this information.

3. As far as we know, no other professional organization has a sliding scale of dues for full members.

Both the Victoria and the Vancouver sections sponsored resolutions at the last annual meeting calling for an increase of $\$ 1.00$ in fees, the increase to be used to help defray expenses of accredited delegates from the outlying sections to the Annual Meetings. One must admit the justification in this, but it is our contention that, at present, the employment of a full-time, paid executive is of more importance to the welfare of the Society as a whole. If a membership drive is instituted along with the increase in fees, there should 
be sufficient funds collected in dues to allow the executive to allocate $\$ 1.00$ per member for the purpose sponsored by the western sections.

We believe that, especially in the last few years since the depression has eased, the Society has made progress in the right direction, and is continuing to do so. There has been a re-awakening of interest in Society affairs and a steady belief by most of the members that we are, at last, heading in the direction that will produce results and recognition. If this progress is not continued and speeded up interest will eventually slacken again. We believe that, by appointing the right man now, the goal we are all aiming for will be reached much sooner and the interest in Society affairs will be heightened.

The Northern Ontario Section realize fully that, in order to put the plan they advocate into effect and make it a success, the support of all the members is essential. Only a small majority in favour of the idea would, if the plan were put into operation, only weaken the Society and result in its failure. The benefits which our Society, in a further stage of development, can give to its members are far in excess of the proposed increased annual fees. While our members would perhaps hesitate to be likened too closely to the members of a Trade Union, still in many respects the relationship is and should be the same. A member of one of the better functioning Trade Unions will willingly pay up to $\$ 100$ per year in annual dues. Surely our Society is worth $\$ 15$ a year to us.

\section{F. L. Flatt}

\section{Society Dues and the Employment of a Full-Time Executive}

In all growing, human associations there arrives, periodically, a need for reorganization of the administrative and financial set-up. In the formation of Societies such as our own the first step is usually the union of a few individuals located close to a common geographic centre, almost always well-known to one another, and probably in frequent contact, apart from the ties of the newly formed Society. The majority of the work is carried on by an unpaid secretary, who is, in fact, the motive power of the organization.

Expansion in membership, both numerically and geographically, results in an increase in the volume of correspondence and, frequently, in the establishment of periodical publications. With these changes come the appointment of one or more positions carrying honoraria. If still greater expansion follows, it usually entails the employment of one or more full-time paid officials. Generally, at various points in the development, minor changes are made to accommodate the employment of low paid, part-time (and not infrequently, incompetent) help--stenographic, accounting, advertisement-soliciting, and so forth. Almost inevitably, as each stage of development approaches, disaffection develops amongst the members. Like an old car, whose owner becomes dissatisfied because it can no longer keep up with newer models, carry the desired load, or take the hills with the same verve, the Society becomes subject to internal criticism. This is the owner's (member's) privilege but he should realize that he can only secure improved performance by the ex. penditure of money. Cussing the old (and hitherto faithful) vehicle wont help and getting out and walking won't bring him to his destination any sooner. 
Our Society has now reached this third stage and it behooves us to calmly consider what we expect from the organization and what, if anything, we are prepared to spend on remodelling it or buying a new machine.

Frankly, the present machine is carrying its maximum load. From our annual revenue of $\$ 2,500$ we spend about $\$ 1,300$ in a direct return to the members through the Chronicles and News Bulletins, and the balance in honoraria, salaries, rental, and minor expenses. For myself, I am averaging about 40 hours monthly on Society affairs and cannot devote any more than that. Our Secretary-treasurer is, I feel sure, devoting considerably more time than myself and presumably has also reached his limit. We, therefore, have a choice of carrying on under our present set-up, making some repairs, or investing in a new vehicle.

Our present membership is approximately 440 . I have estimated that the graduates from our four Canadian forest schools now total 600 . Of these, however, only an estimated 65 per cent. - 390-have remained in forestry work. Foresters from other countries and non-technical men eligible for membership, might furnish another 200 members. There is then a potential membership in this country of 590 , of whom we now have 440 . A completely successful campaign for membership would bring in 150 new members and result in an increase of $\$ 750$ in our annual revenue. However, approximately $\$ 450$ of this would be immediately engulfed in the cost of the additional copies of the two publications, leaving a balance of only $\$ 300$ to add to general revenue.

A graduated scale of dues has been proposed. Using the Salaries Committee's report on Government foresters salaries as a basis for calculation, and assuming that foresters in private employ fall proportionately in the same groups, the graduated scale proposed would yield-on 440 members-an an. nual revenue of approximately $\$ 3,300$, i.e., $\$ 800$ more than at present. This would permit the issuing of two more Chronicles and two more Bulletins a year but would strain the publication cylinder of the engine-already labouring, as admitted, at capacity.

An increase in annual fees to $\$ 10.00$ would return an annual revenue of $\$ 4,700$. Our present set-up costs $\$ 2,500$ a year to run. The difference of $\$ 2,200$ a year, plus the $\$ 375$ released from honoraria, would pay the salary of a full-time officer as proposed, but would not permit the following activities, which I consider are essential to warrant such an appointment:

(a) Travelling expenses to permit an annual visit to each section by the appointed officer;

(b) Full-time employment of a competent office assistant;

(c) Increase in the number and size of Chronicles and News Bulletins,

(d) Organization on a closed-profession basis, including the securing of the necessary legislation to effect this result.

An increase in annual dues to $\$ 15.00$, as detailed in Mr. Flatt's article, preceding this, would permit these varied functions and activities to be carried out.

All of the foregoing calculations are based, of course, on the assumption that an increase in dues would not result in a reduction in membership. Only a trial can determine what would actually result. 
It seems to me, therefore, that our choices are few and clearcut-

1. Continue as we now are with,

(a) An annual fee of $\$ 5.00$;

(b) Four Chronicles and 4 or 5 News Bulletins yearly of the present dimensions;

(c) Replacement every two or three years of the Secretary-treasurer and Editor.

plus an aggressive and continuous membership campaign, which with the natural increment from graduations (they have averaged 25 a year in Canada for the past 20 years) might eventually result in a membership triple our present one. This would certainly take over ten years and might require far longer-or even be impossible in this generation. In the end, however, we would have an annual income that would permit the employment, and fullest value from, a full-time executive officer.

2. Reorganization on a new basis with,

(a) Increase in dues to $\$ 15.00$;

(b) Increase in number and size of Chronicles and News Bulletins to the ultimate goal of 12 Chronicles yearly;

(c) The appointment of a full-time executive offcer and thereby the handling of Society affairs without undue load on a small number of "willing horses."

(d) Ultimately the status of a professional society on a par with the Medical Council of Canada, the Dominion Dental Council, the Provincial Law Societies, the Engineering Institute of Canada, and others.

There are two things we must realize if we select the second choice. First, increased fees must antedate increased benefits. The Society can not accomplish these changes and wait on its members to increase their contributions. You must contribute at the increased rate for at least a year, and possibly two, before expecting any material change. Second, if any considerable reduction in membership results from the increase in dues and is not compensated for by other new members, the proposal falls through and we must revert to choice number one. In that event, my solution would be to credit members who have paid the $\$ 15.00$ fee with two additional years' membership.

There is the picture as I see it. Before you vote recognize that the Society is now doing the best it can with the money available. And if you vote for an increased fee promise yourself to back up that vote with your money.

Which do you want-the old, but still serviceable "jaloppy," or the new streamlined model, which will certainly give you some of the things now lacking although it may not achieve for you all the things you think are your due?

Eric Druce 